\title{
THE EFFECT OF ACTIVITY SCHEDULES TO TEACH APPROPRIATE ACTIVITIES DURING FREE TIME TO STUDENTS WITH AUTISM SPECTRUM DISORDERS
}

\author{
Fayez Maajeeny ${ }^{\mathrm{i}}$ \\ Univeristy of Jeddah, \\ Saudi Arabia
}

\begin{abstract}
:
Background: Recent literature suggests that activity schedules increase engagement and independent play skills while decreasing interfering behaviors for students with autism. Therefore, in this study, four students with diagnosed with autism spectrum disorder were taught to use an activity schedules at free time to examine the effects of it on rate of self-stimulatory behavior. Methods: A multiple baseline design was used to examine these effects. The three students were given an activity schedule housed in a binder with five different recess activities. Activities remained constant throughout the study, but the order was changed. Students followed the activity schedule while experimenters tracked frequency of self-stimulatory behaviors. The frequency was then divided by the duration it took the student to complete the schedule to produce rate data. Findings: Results showed that all three students had high levels of self-stimulatory behavior prior to implementation of the schedule (range of subjects: 6.3-10.5 times per minute). With the implementation of the activity schedule, all three students had significantly decreased rates of self-stimulatory behavior (range of subjects: (1.5 - 2.2 times per minute). The consistent results show that activity schedules decrease the rate of self-stimulatory behavior at recess. Conclusion: These findings support previous research performed over the last several years and confirmed the effectiveness of activity schedules for students with autism.
\end{abstract}

Keywords: autism; autism spectrum disorders; self-stimulation; activity schedule

\section{Introduction}

Teaching appropriate social behavior to students with ASD has received considerable attention in the literature because it is one of the defining deficits characteristic of ASD. There are many appropriate settings for social interactions within a public school. Recess is one time period where students are expected to engage in a variety of behaviors. For

i Correspondence: email fmaajeeny@uj.edu.sa 
example, there are often a variety of play structures that might have slides, stairs, balance beams, tunnels, monkey bars, etc. as well as organized games (e.g., basketball, kickball, soccer, etc.). Such an environment represents an ideal location to teach appropriate play skills to students with ASD. One strategy that could be used to teach appropriate play skills at recess is an activity schedule. Activity schedules have been used by many researchers as an effective intervention to increase on-task behavior inside and outside the classroom. A variety of behaviors have been targeted successfully in these studies including leisure and play skills, transition behaviors, social skills and independent living skills (Knight, Sartini and Spriggs, 2014). The purpose of the present investigation was to examine the effects of an activity schedule on appropriate engagement at recess for students with ASD.

The prevalence of autism spectrum disorders (ASD) has increased dramatically in recent years. One in 59 children in multiple communities in the United States have been identified with ASD (Shaw, Maenner, and Baio, 2020). As a result of this increasing population, the need for more attention from professionals and researchers is necessary to develop effective tools and interventions that address the needs and strengths of individuals with ASD.

The ASD categorization refers to a range of developmental disabilities that includes autism, Asperger syndrome, Rett syndrome, and pervasive developmental disorder not otherwise specified (PDD-NOS; American Psychiatric Association, 2013). The Diagnostic and Statistical Manual of Mental Disorders (DSM-5; 5th ed.) states that individuals with ASD primarily experience deficits in communication, social interaction, and repetitive behaviors.

One of the major characteristics that showed in individuals with ASD that they often resistance to environmental change, changing routine, and transition issues during school day. Many teachers face difficult to manage their students especially between and within transition activity. Recess and leisure time consider one of the critical part of students with ASD daily schedule. Resistance to environmental change for individual with ASD lead to many problem behaviors with inappropriate practices during recess time.

As a result of transition issues, students with ASD limit their ability to independently completing task during school day. Banda, Grimmatt, and Hait (2009) indicated that using activity schedules can help students with ASD in general education classroom to manage transition issues. The strength of activity schedule is critical and should be planned, constructed, and incorporated into existing activities across a number of setting will increase independent transition (Banda, Germmatt, and Hait, 2009)

Many studies have been investigated many strategies to decrease problem behavior and increase engagement or on-task behaviors. Activity schedules was used variety by many researchers as an effective intervention to increase on-task behavior in and outside the classroom. Koyama and Wang (2011) conducted a literature review on the effectiveness of activity schedule. The review proved that activity schedule was effective in increasing the rate of engagement or on-task behavior. In addition, activity 
schedules showed increased of independent task initiation and transition (Kayama and Wang, 2011).

Another study investigated the influence of instruction performed through activity schedules on engaging-in on leisure skills. The result of the study showed that activity schedules was effective in teaching the engaging-in the activity skills and fulfilling the activity skills for children with autism (Cuhader and Diken, 2011).

Moreover, Carlile et al. (2013) conducted study on using activity schedule on iPod touch to teach leisure skills to children with autism. The data were collected on both independent schedule completion and on-task behavior. The result clearly showed that all students increased their schedule completion and a rabid increase of interval of on task.

One part of a typical school day that allows free time is the common elementary school recess period. Machalicek et al. (2007) used activity schedules to see if there was a correlation between increased play and a decrease in challenging behaviors for three children with autism during regular recess at their school.

Specifically, Machalicek et al. (2009) examined the effect of intervention during recess consisting of activity schedule. The result showed that each student was able to learn how to use activity schedules to follow a schedule of play and improved their play. In addition, the results of this study imply that teaching children with autism to use activity schedules can increase task engagement and decrease challenging behaviors. Machalicek et al. (2009) suggested the use of activity schedule to reinforce appropriate play during recess.

The purpose of this study was to examine the effects of an activity schedule on appropriate engagement at free time for three students with ASD. Pending positive results, the use of activity schedules at recess will be continuously implemented and expanded.

\section{Method}

\subsection{Participants}

The study included four students with ASD who were classmates in a self-contained kindergarten through second grade classroom for children with ASD. The participants were selected for the study due to their familiarity with using activity schedules within the classroom environment. Each participant used task-based activity schedules every day during their 30-minute independent work period. All participants in the study also exhibited stereotypic behaviors (e.g., finger flipping, spinning, hand gazing, hand flapping, etc.) and low occurrences of appropriate engagement during recess periods.

Participant 1, was a seven-year-old male and a second-grade student. Following a recent evaluation by a school psychologist, the participant received an educational code of autism. He $t$ was assessed by his teacher using the Childhood Autism Rating Scale, Second Edition (CARS2-ST), and was found to demonstrate autism characteristics that fell within the "severe" range. 
At the onset of the study, Participant 1 was verbal and typically spoke using single words. He also used some rote phrases to communicate such as "I want " and "I see ." His communicative interactions were predominately requests. Within the classroom setting, the classroom staff observed and collected data on throwing or swiping instructional materials and hitting.

Academically, Participant 1 had scattered reading and mathematics skills, which were identified to be in the 30-48 month range based on the Verbal Behavior Milestones Assessment and Placement Program (VB-MAPP). He was able to complete up to a fourstep activity schedule within the classroom with 100\% independence.

Participant 2, was an eight-year-old male and a second-grade student. Following a recent evaluation by a school psychologist, the participant received an educational code of autism. Participant 2 was assessed by his teacher using the CARS2-ST, and was found to demonstrate autism characteristics that fell within the "severe" range.

At the time of the study, Participant 2 was verbal and typically spoke using one word or two to three-word phrases. Most of his communicative interactions were requests and labels. Within the classroom setting, the classroom staff observed and collected data on elopement from the work area and some attention seeking behaviors. Academically, Participant 2 had scattered reading and mathematics skills, which were identified to be in the 48-60-month range based on the VB-MAPP. He was able to complete up to a five-step activity schedule within the classroom with some verbal prompts in order to stay on task.

Participant 3, was a seven-year-old male and a first-grade student. Following a recent evaluation by a school psychologist, the participant received an educational code of autism. Participant 3 was assessed by his teacher using the CARS2-ST, and was found to demonstrate autism characteristics that fell within the "severe" range.

At the onset of the study, Participant 3 was verbal and typically spoke using two to four-word phrases. His communicative interactions were predominately requesting and labels, and he occasionally made comments. Within the classroom setting, the classroom staff observed and collected data on non-compliant behaviors and spitting.

Academically, he had scattered reading and mathematics skills, which were identified to be in the 48-60-month range based on the VB-MAPP. He was able to complete up to a five-step activity schedule within the classroom with $100 \%$ independence.

Participant 4, was a seven-year-old male and a second-grade student. Following a recent evaluation by a school psychologist, the participant received an educational code of autism. Participant 4 as assessed by his teacher using the CARS2-ST, and was found to demonstrate autism characteristics that fell within the "severe" range.

At the time of the study, Participant 4 was verbal and typically spoke in two to three-word phrases, and most of his communication interactions were requests or labels. Within the classroom setting, He exhibited non-compliance within the classroom setting and staff measured its occurrence on a daily basis. 
Academically, Participant 4 had scattered reading and mathematics skills, which were identified to be equivalent to 60 months of age on a developmental scale based on the Brigance Inventory of Early Development. He was able to complete up to a five-step activity schedule within the classroom with 100\% independence.

\subsection{Setting}

All four participants were attending a primary elementary school, which included students in kindergarten through the second grade. At the time of the study, the four participants were classmates and were students in a self-contained kindergarten through second grade classroom for children with ASD. The classroom included a total of six students with one lead teacher and two classroom para-educators. The participants' peers were all males.

The elementary school playground was the setting for both the baseline and intervention phases of this study. The playground was outside, behind the elementary school building and was fenced due to proximity to a local highway. Within the fencedin playground were three different play structures separated from each other by approximately about 6-8 feet. The following equipment was present on these structures: stairs, slides, climbing grids, balance beams, tunnels, monkey bars, fire poles, and steering wheels. The structures were within an area of woodchips and dirt. The playground also had a large blacktop with hopscotch and foursquare games painted onto it, four laundry baskets, a container of bean bags, and three hula hoops.

During the implementation of this study, a total of nineteen students were present on the playground from three different classrooms. All students were enrolled in an autism program and they ranged from three to eight years of age, and had varying characteristics. During the implementation of the study, there were also eight para educators on the playground. For the purposes of the study, the classroom teacher was also outside on the playground to facilitate the implementation of the intervention. The duration of the recess period was approximately 30 minutes.

\subsection{Materials}

The activity schedule that the participants used during this recess period was housed in a binder. A binder was used to display the activity schedule because it closely resembled the task-based activity schedules the participants used in the classroom for independent work during each school day.

Inside the binder, each page had a horizontal strip of Velcro. One photograph of a typical playground feature was placed on the strip of Velcro. The photographs that were used were of the actual playground equipment found on the playground. The photographs were measured at one-inch squares, which were modeled after Picture Communication Symbols (PCS). Above each photograph was the typed name or label of the specific piece of equipment.

The binder featured six pages that each had a different photograph on the Velcro strip. The same six photographs were used throughout the study, and included a balance 
beam, bean bags and basket, stairs, small tunnel and slide, hula hoops, and large tunnel. The order of the photographs remained the same during each session.

\subsubsection{Response Definition and Measurement Procedures}

Each participant in the study displayed low occurrences of appropriate engagement during recess periods. For the purposes of the study, appropriate engagement involved using the playground equipment based on its intended function. The identified examples and non-examples of appropriate engagement as they relate to specific equipment found on the playground are shown in Table 1. Appropriate engagement was also defined as involvement with the activity schedule. This included using the activity schedule to identify the appropriate area, traveling to the designated area, and completing the activity with the specified playground equipment that was photographed (e.g., walking on the balance beam, taking out and tossing bean bags back into a basket, going up the stairs, crawling through a tunnel and going down a slide, hopping through hula hoops placed on the ground, and crawling through a larger tunnel).

Data on appropriate engagement were collected using partial interval recording. The investigators used ABC Data Pro (Romanczyk, Gillis, \& Callahan, 2011). ABC Data Pro allows for the collection of frequency, interval, and $A B C$ data, for multiple participants and multiple target behaviors. Using the app, the investigators observed a participant for 10 seconds and then took 10 seconds to record or identify whether or not the participant exhibited appropriate engagement. The investigators measured appropriate engagement for a total of six minutes or 36 ten-second intervals, which included observation and recording periods, for each of the participants.

\subsubsection{Experimental Design and Procedures}

A multiple baseline design across four participants was used to determine the effects of activity schedules on appropriate engagement at recess.

\section{a. Baseline}

During baseline, the adult instructed the student to "Go play." From a distance, the investigators then observed and followed the participant around the playground. The participant was able to move freely around the playground and access any equipment or open space that was desired. The investigators did not provide any prompts to the participant during this time, and was merely acting as a "shadow" to the participant. The investigators followed the participant for a duration of six minutes and no consequences were provided for the presence or absence of appropriate engagement. This procedure was replicated for each of the four participants. It is important to note that the classroom teacher was not present on the playground during the collection of baseline data. At the end of each observation, the investigators selected and followed another student, as students continued to move freely around the playground. 


\section{b. Intervention}

During the intervention phase of this study, each participant followed the activity schedule housed in the binder that was described previously. The classroom teacher began the intervention by stating, "It's time to do your schedule." At this time, the classroom teacher also handed the binder to the participant.

After the classroom teacher provided the instruction, the participant opened the binder to the first page and walked to the first piece of equipment that was pictured. Once the participant completed the activity with the specified playground equipment, the participant turned the page in the binder to see the next piece of equipment that was photographed. The participant then traveled to the designated area and completed the activity with the specified playground equipment. This cycle continued for six activities with different equipment until the completion of the activity schedule. The participant would then start the activity schedule again until six minutes elapsed. The participant completed the activity schedule twice before the time elapsed. At the completion of the activity schedule and six-minute period, the participant returned to free play during recess time. Free play during recess was highly reinforcing to all four participants in the study; therefore, no further reinforcement was necessary to motivate participants to complete the activity schedule.

On occasion, the participants required prompting to complete the activity with the specified playground equipment. For example, participants required gestural and verbal prompts to crawl through the large tunnel instead of remaining inside of it, or to toss only one bean bag at a time into a basket. Overall, prompts were used to aid the participant in completing the activity correctly. Both social praise and encouragement were also provided as students completed the activity schedule.

\section{c. Reliability}

The primary observer in the baseline and intervention phases was a doctoral student at a local university who was aware of the purpose of the study. A second observer independently recorded whether or not the participant exhibited appropriate engagement. The second observer was also a doctoral student at a local university and was also aware of the purpose of the study.

Reliability data were collected for $45 \%$ of all probes. Reliability was calculated by adding the number of agreements of occurrence and the agreements of nonoccurrence of appropriate engagement. The calculated sum of agreements was then divided by the total number of observation intervals. The total number of observation intervals for the sixminute period was 18 . The overall average calculated inter-observer agreement was $98 \%$ (range, $83.3 \%-100 \%$ ).

\section{Results}

Figure 1 shows the percentage of 10-s intervals with appropriate engagement during baseline and intervention for each student. All four students exhibited low levels of 
appropriate engagement during baseline. The mean scores during baseline were $0,8.3 \%$ (range, 0-16.7\%), 5.6\% (range, 0-33.3\%) and 6.1\% (range, 0-27.8\%) for P1, P2, P3 and P4, respectively. Introduction of the activity schedules resulted in immediate and substantial changes in levels of appropriate engagement. Responding during intervention averaged 79.6\% (range, 38.9-94.4\%), 93.7\% (range, 72.2-100\%), 81.5\%, (range, 61.1-100\%), and 96.3\% (range, $94.4-100 \%$ ) for P1, P2, P3, and P4, respectively.

Figure 1: The average percentage of occurrence within interval for appropriate engagement using a multiple baseline design.

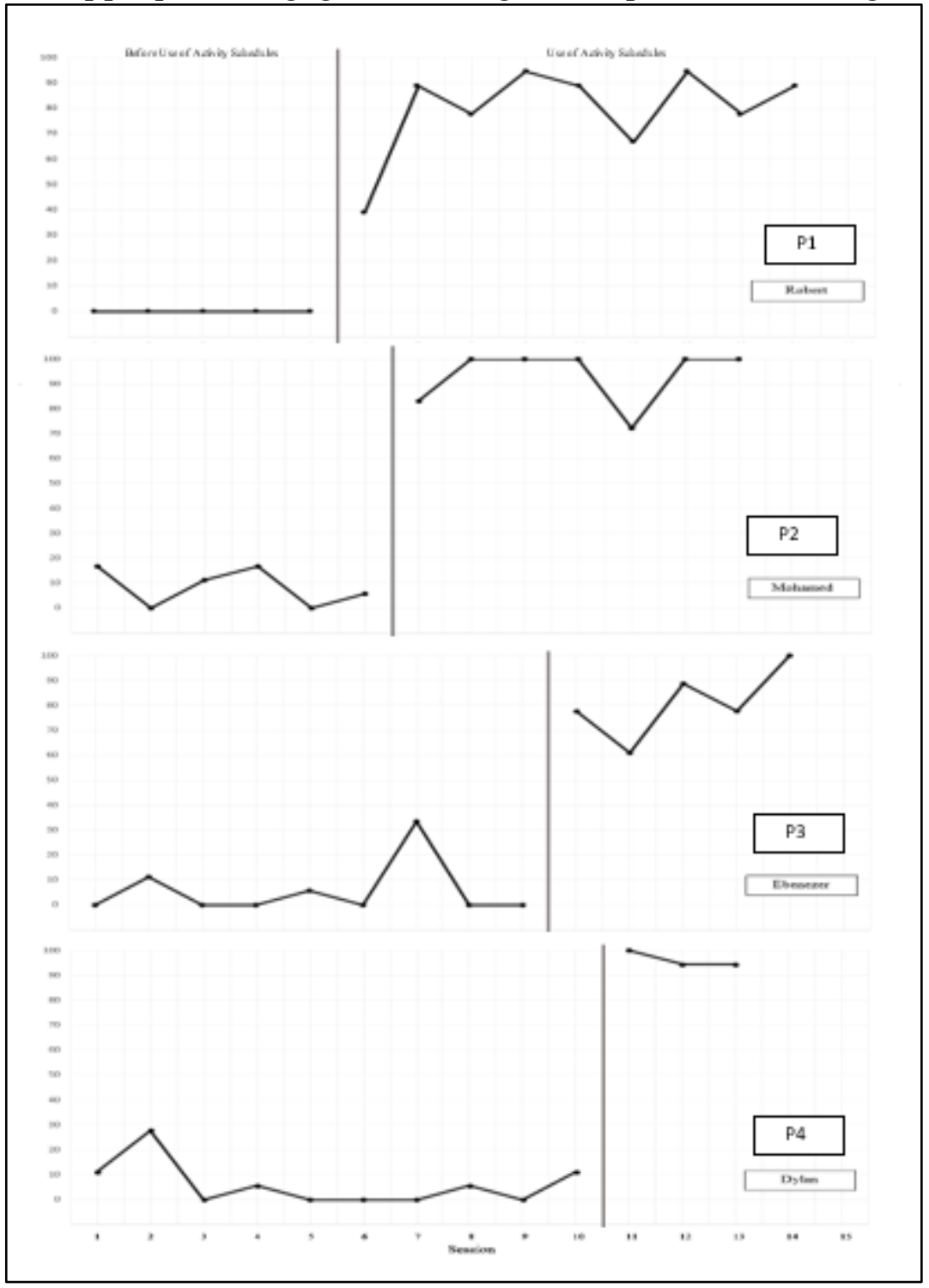

Overall, this study showed that the implementation of an activity schedule at recess for three students with autism had a very powerful effect. The results in this study were very consistent across the three subjects. In baseline, all three subjects had high levels of self-stimulatory behavior. Although these levels varied (6.3, 10.5, 8.9 behaviors per minute) the behavior occurred often and was interfering to the student playing appropriately at recess. When the intervention of the activity schedule was implemented, 
the effect was immediate. There was a sudden drop in level within the data. This was true for all three of the subjects in this study. All three subjects had significantly lower levels of self-stimulatory behavior during the intervention phase $(1.9,1.5,2.2)$.

Before activity schedules were implemented at recess, the thirty-minute time period was largely unstructured. All three subjects have autism characteristics that are considered "severe," meaning that they have large deficits in socialization, communication, and behavior. Independent and group play skills fall into these categories. Because the students were never taught the play skills to use the equipment appropriately or to interact with other students, they used this time period to stimulate themselves by exhibiting these behaviors. The students also lacked motivation to play on the equipment or to interact with others. They found it much more motivating to engage in these self-stimulatory behaviors. Once the activity schedules were implemented, the time period turned into a more structured time. The students became more engaged, and therefore, self- stimulatory behaviors decreased significantly. Therefore, the activity schedules engaged the student's during a previously unstructured time period. In structuring the time at recess, self-stimulatory behaviors decreased.

\section{Discussion}

The findings from this study demonstrate conclusively the effectiveness of visual pictures schedules on increasing the appropriate engagement of students with ASD during recess. All of the students demonstrated rapid increases in their appropriate engagement with the playground equipment. These findings are consistent with previous research demonstrating the effectiveness of activity schedules to teach a variety of other behaviors to students with ASD (Carlile et al., 2013; Cuhadar, 2011; Krantz, MacDuff and McClannahan, 1993; Lee, Odom and Loftin 2007; Morrison and Rosales-Ruiz, 1997; Nuzzolo-Gomez, 2002; O'Reilly et al., 2005). The effectiveness of the intervention may have been influenced by the participant's history of using task-based activity schedules during their 30-minute independent work period in the classroom. Applying the intervention to students without this previous history may require additional training in order to reach the same level of effectiveness. It would also have been helpful to obtain generalization and maintenance data; unfortunately, the school year ended before those data could be obtained. It is also important to note that the intervention was designed to increase the participants' engagement with the playground equipment. Future research should determine if activity schedules can be used to promote interactive use of the playground equipment that would include typical peers. It seems possible that the activity schedules could be used to help students with ASD initiate the interaction and then rely on the peers to maintain the interaction over time.

\section{Conflict of Interest Statement}

The author(s) further declare(s) that the study holds no conflicts of interest. 


\begin{abstract}
About the Author(s)
Dr. Fayez Suliman Maajeeny is Assistant Professor of Special Education at the University of Jeddah. Currently, he is the vice dean of admission and registration. He earned his PhD from the University of Maryland- United States of America, 2017. His area of interest is focused on instructional methods of teaching students with autism spectrum disorders, strategies for inclusion of students with disabilities, empirically based instructional methodology, applied behavior analysis, and single-case research methodology. He has a numerous conference presentations and publications on the use of various technologies with students who have autism spectrum disorders.
\end{abstract}

\title{
References
}

American Psychiatric Association. (2013). Diagnostic and statistical manual of mental disorders (5th ed., DSM-V.). doi:10.1176/appi.books.9780890423349

Banda, D. R., Grimmett, E., \& Hart, S. L. (2009). Activity Schedules: Helping Students with Autism Spectrum Disorders in General Education Classrooms Manage Transition Issues. Teaching Exceptional Children, 41, 16-21. doi:10.1177/004005990904100402

Carlile, K. A., Reeve, S. A., Reeve, K. F., \& DeBar, R. M. (2013). Using activity schedules on the iPod touch to teach leisure skills to children with autism. Education and treatment of children, 36, 33-57. doi:10.1353/etc.2013.0015

Cuhadar, S., \& Diken, I. H. (2011). Effectiveness of instruction performed through activity schedules on leisure skills of children with autism. Education and training in autism and developmental disabilities, 46, 386-398.

Gillis, J. M., Callahan, E. H., \& Romanczyk, R. G. (2011). Assessment of social behavior in children with autism: The development of the Behavioral Assessment of Social Interactions in Young Children. Research in Autism Spectrum Disorders, 5, 351-360.

Knight, V., Sartini, E., \& Spriggs, A. D. (2015). Evaluating visual activity schedules as evidence-based practice for individuals with autism spectrum disorders. Journal of autism and developmental disorders, 45, 157-178. doi:10.1007/s10803-014-2201-z

Koyama, Takanori (2011). Use of activity schedule to promote independent performance of individuals with autism and other intellectual disabilities: A review. Research in developmental disabilities, 32, 2235-2242. doi:10.1016/j.ridd.2011.05.00

Krantz, P. J., MacDuff, M. T., \& McClannahan, L. E. (1993). Programming participation in family activities for children with autism: parents' use of photographic activity schedules. Journal of Applied Behavior Analysis, 26, 137-138. doi:10.1901/jaba.1993.26-137

Lee, S., Odom, S. L., \& Loftin, R. (2007). Social engagement with peers and stereotypic behavior of children with autism. Journal of Positive Behavior Interventions, 9, 67 79. doi:10.1177/10983007070090020401 
Machalicek, W., O’Reilly, M. F., Beretvas, N., Sigafoos, J., \& Lancioni, G. E. (2007). A review of interventions to reduce challenging behavior in school settings for students with autism spectrum disorders. Research in Autism Spectrum Disorders, 1, 229-246. doi:10.1016/j.rasd.2006.10.005.

Machalicek, W., Shogren, K., Rispoli, M., O’Reilly, M. F., Franco, J. H., \& Sigafoos, J. (2009). Increasing play and decreasing the challenging behavior of children with autism during recess with activity schedules and task correspondence training. Research in Autism Spectrum Disorders, 3, 547-555. doi:10.1016/j.rasd.2008.11.003

Morrison, K., \& Rosales-Ruiz, J. (1997). The effect of object preferences on task performance and stereotypy in a child with autism. Research in Developmental Disabilities, 18, 127 - 137. doi:10.1016/S0891-4222(96)00046-7

Nuzzolo-Gomez, R., Leonard, M. A., Ortiz, E., Rivera, C. M., \& Greer, R. D. (2002). Teaching children with autism to prefer books or toys over stereotypy or passivity. Journal of Positive Behavior Intervention, 4, 80 - 87. doi:10.1177/109830070200400203

O’Reilly, M., Sigafoos, J., Lancioni, G., Edrisinha, C., \& Andrews, A. (2005). An examination of a classroom activity schedule on levels of self-injury and engagement for a child with severe autism. Journal of Autism and Developmental Disorders, 35, 305-311. doi: 10.1007/s10803-005-3294-1

Shaw, K. A., Maenner, M. J., \& Baio, J. (2020). Early identification of autism spectrum disorder among children aged 4 years-Early Autism and Developmental Disabilities Monitoring Network, six sites, United States, 2016. MMWR Surveillance Summaries, 69, 1. doi:10.15585/mmwr.ss6904a1 
Fayez Maajeeny

THE EFFECT OF ACTIVITY SCHEDULES TO TEACH APPROPRIATE ACTIVITIES DURING

FREE TIME TO STUDENTS WITH AUTISM SPECTRUM DISORDERS

Creative Commons licensing terms

Authors will retain the copyright of their published articles agreeing that a Creative Commons Attribution 4.0 International License (CC BY 4.0) terms will be applied to their work. Under the terms of this license, no permission is required from the author(s) or publisher for members of the community to copy, distribute, transmit or adapt the article content, providing a proper, prominent and unambiguous attribution to the authors in a manner that makes clear that the materials are being reused under permission of a Creative Commons License. Views, opinions and conclusions expressed in this research article are views, opinions and conclusions of the author(s). Open Access Publishing Group and European Journal of Special Education Research shall not be responsible or answerable for any loss, damage or liability caused in relation to/arising out of conflict of interests, copyright violations and inappropriate or inaccurate use of any kind content related or integrated on the research work. All the published works are meeting the Open Access Publishing requirements and can be freely accessed, shared, modified, distributed and used in educational, commercial and non-commercial purposes under a Creative Commons Attribution 4.0 International License (CC BY 4.0). 